\title{
Remating in Anastrepha sp.1 aff. fraterculus (Diptera: Tephritidae): An Analysis Using rose Mutation
}

\author{
Pietro Enrico Vicari, André Luiz Paranhos Perondini and Denise Selivon \\ Department of Genetics and Evolutionary Biology, Institute of Bioscience, University of São Paulo, São Paulo 05508-090, Brazil
}

\begin{abstract}
The propensity of females to cross with more than one male is a relevant aspect in tephritid fruit fly biology since many species are pests of fruticulture. The knowledge about mating systems of a target pest-species is crucial for defining efficient strategies for insect population control, e.g., for the sterile insect technique (SIT). The aim of this study was to evaluate the propensy to remate of the tephritid Anastrepha sp.1 aff. fraterculus females. For this purpose it was used an autosomic recessive mutation, rose, that affects eye-color, in two designed experimental systems: one in which wild-type and rose males were sequentially offered to cross with rose females and another one in which the rose females had to choose to cross with a wild-type, to a rose male or to both (remate). By simple analyses of the progeny phenotypes it was possible to recognize whether the females had remated or not. About a third of the females produced mixed progenies with wild-type and rose individuals, thereby indicating remating during the week the experiment lasted. Data indicated that remating rate was higher than previously reported for this species, and it could be shown that the sperms derived from the different males the females had crossed had been used in egg fertilization.
\end{abstract}

Key words: Behavior, mate choice, mating, polyandry.

\section{Introduction}

Fruit flies (Diptera: Tephritidae) lay their eggs inside fruits, where larval development occurs. As many fruits are of commercial importance, the harm caused by these insects can lead to large economic losses [1]. In the Neotropics, one species of outstanding importance is Anastrepha fraterculus (Wiedemann). A. fraterculus (sensu lato) comprises a complex of cryptic species, the $A$. fraterculus complex, in which eight morphotypes have been recognized so far, three of which occur in Brazil, viz., A. sp.1 aff. fraterculus, A. sp.2 aff. fraterculusand $A$. sp.3 aff. fraterculus [2-6]. Hence, the focus on understanding the biological aspects of these species, aims to improve population-control strategies [7-9]. A relevant and primordial aspect related to the knowledge of the reproductive strategy of a given species is whether it has a monoandric-females copulate with only one male-or polyandric

Corresponding author: Denise Selivon, associate professor, research fields: genetic and evolutionary biology. reproductive system - females copulate with different males [10].

A prior analysis of the mating behavior of $A$. fraterculus (s.l.) showed that, on an average, females mate three times during their life-time [11]. Later on, several mechanisms were found to be involved in the control of female receptivity to remate, such as sperm depletion and storage, accessory gland proteins and the rate of remate in a sample of $A$. fraterculus (s.l.) from Argentina [12-15]. It was also shown that such rate increases during the female's life-time and that the propensity to remate is about $10 \%$ in the first week after the first copula $[12,13]$. However, the experimental procedures so far employed in the re-mating studies in such species, involved intense manipulation of the flies, which might have disturbed the mating pair, thereby interfering in the results. In addition, previous analyses did not investigate whether the spermatozoa from different males actually fertilized the eggs.

In order to minimize the handling of flies during the experiments, improving the accuracy of results, an 
alternative methodology was employed. As described in the present report, this was based on the analysis of progenies produced by flies bearing the rose mutation, an autosome recessive mutation affecting the eyes color, and previously described for this species [16]. Using individuals bearing the rose mutation, it was possible to ascertain some aspects related to remating events without the need to manipulate the mating pairs, as well as to verify if the spermatozoa from different males resulted in fertilization.

\section{Materials and Methods}

\subsection{Strains}

Pure lineages of wild-type (Wt) and rose mutant specimens of $A$. sp.1 aff. fraterculus were obtained from laboratory colonies $[4,16]$. Wild-type flies have reddish-colored eyes with bluish-green iridescence, whereas rose mutants have yellowish-orange eyes with roseate iridescence (Fig. 1). The colonies were maintained according to laboratory standard procedures [4]. Guavas (Psidium guajava L.) were provided as oviposition sites and larval development. Pupae were retrieved, and after emergence, adult flies were sorted by sex. Virgin flies (21 d after emergence for females and $15 \mathrm{~d}$ for males) were supplied with water and an artificial diet (corn meal protein hydrolysate, sugar and water) and kept at a controlled temperature $\left(26 \pm 2{ }^{\circ} \mathrm{C}\right)$ and humidity $(65 \% \pm 2 \%)$. Artificial luminosity was supplied by fluorescent lamps obeying a circle of $12 \mathrm{~L}: 12 \mathrm{D}$ besides the natural lighting coming from a window.

\subsection{Remating in an Experimental Successive Male System}

Twenty virgin and sexually mature rose females were individually transferred to plastic cages $(14 \mathrm{~cm} \times$ $13.5 \mathrm{~cm} \times 12 \mathrm{~cm}$ ) with a wild-type male in each one. Water and food were supplied ad libitum. The pairs were left to cross during a week, and one guava per cage was furnished as oviposition site. After this period, the wild-type males were removed and the recovered guavas were maintained in laboratory conditions until the larvae reach the pupal stage. The females were kept in the cages and a new guava was supplied in each cage during this second week. At the beginning of the third week, one rose male was introduced in each cage and the new pairs were left to cross for one week and one guava was furnished per cage. Hence, during the first week, the females could cross to wild-type males and began the oviposition and during the second week, the females continued to lay eggs that were fertilized by spermatozoa produced by these males. In the third week, with the introduction of rose males, females could remate or not and the progeny produced by each female might bear three possible phenotypes: (1) only wild-type flies if the females did not remate, (2) only individuals bearing the rose phenotype if the females crossed just with the rose male and (3) of mixed progenies with wild-type and rose individuals. Four crosses were

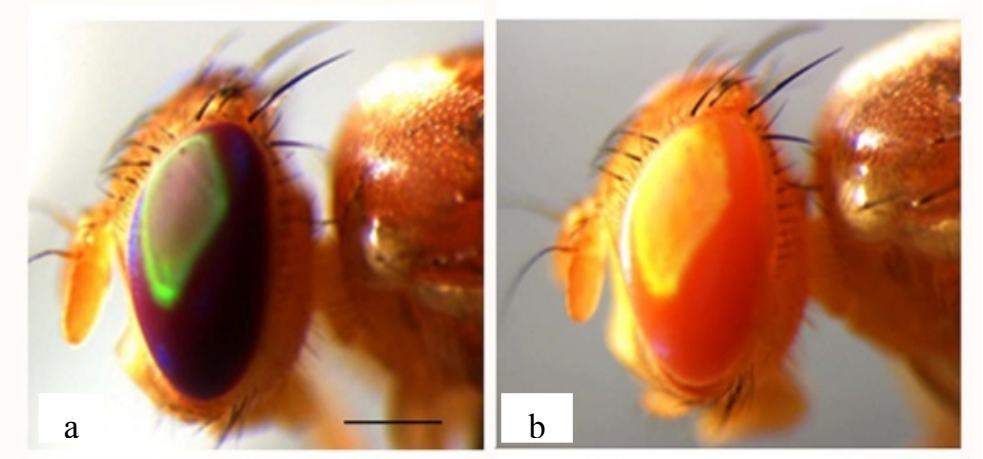

Fig. 1 Heads of Anastrepha sp.1 aff. fraterculus exhibiting the wild-type (a) and rose (b) eye phenotypes. Bar $=500 \mu \mathrm{m}$. 
discarded after the female death. The data were analyzed by tests of proportions implemented in Statistica 6.0 software (StatSoft, Inc. ${ }^{\circledR}$ ).

\subsection{Remating in an Experimental Female Choice System}

Thirty virgin and sexually mature rose females were individually transferred to plastic cages $(14 \mathrm{~cm} \times$ $13.5 \mathrm{~cm} \times 12 \mathrm{~cm}$ ). Two sexually mature virgin males, one rose and one wild-type, were introduced in each cage. Water and food were supplied ad libitum and guavas were made available as oviposition sites. Flies were kept in the cages for a week without any kind of interference. Guavas were retrieved and after larval development, pupae were recovered and kept under standard laboratory conditions until adult emergence. Progenies from each cross were inspected and the phenotypes of flies were registered. Analysis of each progeny allowed to infer the type of crossing that has occurred as described above. Three crosses were discarded after the female's death. The data were analyzed by tests of proportions implemented in Statistica 6.0 software (StatSoft, Inc. ${ }^{\circledR}$ ).

\section{Results}

In the experimental successive male system, the progenies produced by the 16 individual pairs of mating during the first two weeks, were composed only by wild-type individuals, as expected since the rose females were inseminated by wild-type males during the first week of the experiment. During the third week, progenies of three types were obtained: in $12.5 \%$ of the crosses, only individuals displaying the wild-type phenotype were found; in $62.5 \%$ of crosses only flies with the rose phenotype were recovered and in $25.0 \%$ of the crosses, mixed progenies with wild-type and rose individuals were obtained. The data of the two latter types of progenies, clearly show that $87.5 \%$ of the females had remated with the rose males introduced in the cages.

In the experimental female choice system, 13 out 27 (48.1\%) of the crosses, the rose females produced offspring bearing only the wild-type phenotype, indicating that these females had crossed only with wild-type males. They produced a total of 313 flies, on average of 24.1 flies per female. In other 5 out 27 $(18.5 \%)$ of crosses, the females produced offspring bearing only the rose phenotype, thereby indicating they crossed only to rose males. In this case, a total progeny of 63 individuals were produced, on an average 12.6 flies per female. Differences in the proportion of offspring produced by the females involved in both types of crossing were significant (Table 1). On the other hand, in 9 out 27 (33.3\%) of the crosses, the females produced a total of 135 individuals, 72 bearing the wild-type and 63 the rose phenotypes, the difference being non-significant $\left(\chi^{2}\right.$ Yates $=0.243, p=$ $0.626)$. On an average, 15.0 flies were produced per female, the proportions differing significantly from crosses involving only wild-type males, but non-significantly to crosses with only rose males (Table 1). Hence, cross type (3) indicate that a remating rate of $33.3 \%$ occurred during the period of one week after the females and males had first been placed in contact for crossing. This rate is significantly higher $\left(\chi^{2}\right.$ Yates $\left.=13.84, p<0.001\right)$ than the remating rate of $10 \%$ previously reported during a like one-week-period for A. fraterculus (s.l.) from Argentina [12, 13].

Table 1 Progeny phenotypes, inferred crosses, progeny size and statistical comparison of mean of flies per cross.

\begin{tabular}{|c|c|c|c|c|c|c|}
\hline \multirow{2}{*}{$\begin{array}{l}\text { Progeny } \\
\text { phenotypes }\end{array}$} & \multicolumn{2}{|c|}{ Inferred crosses } & \multicolumn{2}{|l|}{ Progenies } & \multicolumn{2}{|c|}{ Mean/cross } \\
\hline & $\mathrm{N}$ & Types & $\mathrm{N}$ & Mean/cross (s.d.) & Comparison & $p$ values \\
\hline $\mathrm{Wt}$ & 13 & (1) rose $+\times \mathrm{Wt} \hat{O}$ & 313 & $24.1(15.6)$ & $(1) \times(2)$ & $p<0.001^{* *}$ \\
\hline rose & 5 & (2) rose $\phi \times$ rose $\widehat{\sigma}$ & 63 & $12.6(10.2)$ & $(1) \times(3)$ & $p<0.001^{* *}$ \\
\hline $\mathrm{Wt}+$ rose & 9 & (3) $\mathrm{Wt} \hat{\delta} \times$ rose $Q \times$ rose $\hat{\sigma}$ & 135 (72 Wt; 63 rose) & $15.0(14.2)$ & $(2) \times(3)$ & $p=0.128^{\mathrm{ns}}$ \\
\hline
\end{tabular}

Wt: wild type; s.d.: standard deviation; $* *$ : significant; ns: non significant. 


\section{Discussion}

The characterization of a given species as either monoandrous or polyandrous, besides adding information on ecological aspects, is crucial for the establishment of population control strategies of pest-species, such as the sterile insect technique (SIT) which has been employed for some fruit fly species. In the present study high remate frequencies of $87.5 \%$ and of $33.3 \%$ were found, respectively, in the first and second experimental systems, respectively, but the frequency may be even higher since in the experiments remating with the same type of male could not be estimated. As these frequencies are near and higher to the threshold of $40 \%$ proposed by Torres-Vila et al. [10] to classify an insect species as polyandrous, the data implies that $A$. sp.1 aff. fraterculus is certainly one of these, as was reported in A. fraterculus (s.l.) [13]. However, in the article, it was not specified the entity of the $A$. fraterculus complex that was employed although previous analyses have shown that $A$. sp.1 aff. fraterculus does occur in Argentina [17]. Additionally, the results herein obtained clearly showed not only that remate had occurred but also that spermatozoa from both type of males have been successful in fertilizing eggs.

The frequency of $87.5 \%$ of remating is higher than the frequency of about $45 \%-50 \%$ described for $A$. fraterculus (s.l.) [13], but the value is very close to that described by Lima et al. [11] that found a frequency of $90 \%$ for $A$. fraterculus (s.l.) considering their entire reproductive life. It is surprising since the experiments herein described lasted just three weeks after the females reached their sexual maturity. The high value may be explained if one assumes that after the first two weeks, the females that had mated with the wild-type males would had enough time to empty their spermathecae. Since the acceptance of females to remate seems to be related to the replacement of their stored sperm supplies, it is not difficult to understand the high frequency of females who have remated with the rose males at the third week. It is noteworthy that some females produced only flies with the wild-type phenotype while others produced progenies with both, wild-type and rose individuals. This result clearly demonstrate that females accepted remating, even if their spermathecae still had sperms from the previous males with which they had crossed. So, this means that a reduction in the sperm supply may be enough for the females to accept a remate, although the exact threshold of the sperm supply remains to be elucidated. The relationship between remating frequency and replenish of sperm supply is a well known phenomenon in Diptera [18], and the tephritid fruit flies are no exception [13, 19, 20].

In fact, remating frequency varies with the experimental conditions $[15,18]$ and the conditions in the studies on remating in the tephritid fruit flies were certainly variables, which could explain the different results. Abraham et al. [13] detected in A. fraterculus (s.l.) a frequency of about $10 \%$ of remating $7 \mathrm{~d}$ after the females reached sexual maturity and the highest remating frequencies of $45 \%$ to $50 \%$ after a period of about $30 \mathrm{~d}$, leading the authors to postulate that in nature this species seems to be monoandrous. However, the remating rate of $33.3 \%$ which occurred in the time elapsed of just one week in the present experiments, indicated that remating may occur in a higher frequency than seems at first glance in $A$. sp.1 aff. fraterculus. Moreover, the data also indicated that the females would have a shorter refractory period than that found in A. fraterculus (s.l.) from Argentina [13].

Although handling was at a minimum, it must be considered that the results were obtained under laboratory conditions. Female choice was forcibly between only two types of males, which possibly may not be a prevalent condition in the field, due to complex reproductive behaviors and interaction with other flies [13, 21, 22]. 


\section{Conclusions}

The design of involved in the present study, using a phenotypic marker and conditions that did not disturbed the mating pairs, provided significant improvements for the understanding of mating behavior of $A$. sp.1 aff. fraterculus. Notwithstanding, the tests with rose flies added relevant information, not only that the frequency of remating may be higher than previously described but also indicate that the average refractory period after the first-mating may be shorter than estimated in prior studies. The experiments also showed for the first time, that the sperms of different males involved in the remating were successful in egg fertilization. Moreover, the results clearly demonstrate that the females remated even though the spermathecae are not completly empty. Hence, the data obtained with the present experimental systems pose difficulties to the suggestion that in nature A. fraterculus (s.l.) is functionally monogamous. These facts are extremely relevant for academic laboratory inferences about mating systems of tephritid flies, and for practical purposes, must be taken into account when developing control strategies involving this pest-species.

\section{Acknowledgments}

The work was funded by Fundação de Amparo à Pesquisa do Estado de São Paulo (FAPESP Proc. 2016/00782-7). The first author is a Ph.D. student supported by a scholarship from Conselho Nacional de Desenvolvimento Científico e Tecnológico (CNPq, 134297/2014-8).

\section{References}

[1] White, I. M., and Elson-Harris, M. M. 1992. Fruit Flies of Economic Importance: Their Identification and Bionomics. Wallingfford, UK: CAB International.

[2] Selivon, D., and Perondini, A. L. P. 1998. "Eggshell Morphology in Two Cryptic Species of the Anastrepha fraterculus Complex (Diptera: Tephritidae)." Ann. Entomol. Soc. Am. 91: 473-8.

[3] Selivon, D., Perondini, A. L. P., and Morgante, J. S. 1999. "Haldane's Rule and Other Aspects of Reproductive
Isolation Observed in the Anastrepha fraterculus Complex (Diptera: Tephritidae)." Genet. Mol. Biol. 22: 507-10.

[4] Selivon, D., Perondini, A. L. P., and Morgante, J. S. 2005. "A Genetic-Morphological Characterization of Two Cryptic Species of the Anastrepha fraterculus Complex (Diptera: Tephritidae)." Ann. Entomol. Soc. Am. 98: 367-81.

[5] Hernández-Ortiz, V., Bartolucci, A. F., Morales-Valles, P., Frías, D., and Selivon, D. 2012. "Cryptic Species of the Anastrepha fraterculus Complex (Diptera: Tephritidae): A Multivariate Approach for the Recognition of South American Morphotypes." Ann. Entomol. Soc. Am. 105: 305-18.

[6] Hernández-Ortiz, V., Canal, N. A., Salas, J. O. T., Ruíz-Hurtado, F. M., and Dzul-Cauich, J. F. 2015. "Taxonomy and Phenotypic Relationships of the Anastrepha fraterculus Complex in the Mesoamerican and Pacific Neotropical Dominions (Diptera: Tephritidae)." Zookeys 540: 95-124.

[7] Aluja, M., and Mangan, R. L. 2008. "Fruit Fly (Diptera: Tephritidae) Status Determination: Critical Conceptual, Methodological and Regulatory Considerations." Ann. R. Entomol. 53: 473-502.

[8] Cladera, J. L., Vilard, J. C., Juri, M., Paulin, L. E., Cecilia Giardini, C. M., Gómez Cendra, V. P., Segura, D. F., and Lanzavecchia, S. B. 2014. "Genetics and Biology of Anastrepha fraterculus: Research Supporting the Use of the Sterile Insect Technique (SIT) to Control This Pest in Argentina." BMC Genet. 15 (suppl 2): S12.

[9] Hendrichs, J., Vera, T., DeMeyer, M., and Clarke, A. R. 2015. "Resolving Cryptic Species Complexes of Major Tephritid Pests.” ZooKeys 540: 5-39.

[10] Torres-Vila, L. M., Rodriguez-Molina, M. C., and Jennions, M. D. 2004. "Polyandry and Fecundity in the Lepidoptera: Can Methodological and Conceptual Approaches Bias Outcomes?” Behav. Ecol. Sociobiol. 55: 315-24.

[11] Lima, I. S., Howse, P. E., and Salles, L. A. B. 1994. "Reproductive Behavior of the South American Fruit Fly Anastrepha fraterculus (Diptera: Tephritidae): Laboratory and Field Studies." Physiol. Entomol. 19: 271-7.

[12] Abraham, S., Goane, L., Cladera, J. A., and Vera, M. T. 2011a. "Effects of Male Nutrition on Sperm Storage and Remating Behavior in Wild and Laboratory Anastrepha fraterculus (Diptera: Tephritidae) Females." J. Insect Physiol. 57: 1501-9.

[13] Abraham, S., Goane, L., Rull, J., Cladera, J., Willink, E., and Vera, M. T. 2011. "Multiple Mating in Anastrepha fraterculus Females and Its Relationship with Fecundity and Fertility." Entomol. Exp. Appl. 141 (1): 15-24. 

Analysis Using rose Mutation

[14] Abraham, S., Cladera, J., Goane, L., and Vera, M. T. 2012. "Factors Affecting Anastrepha fraterculus Female Receptivity Modulation by Accessory Gland Products." J. Insect Physiol. 58: 1-6.

[15] Abraham, S., Rull, J., Mendoza, M., Liendo, M. C., Devescovi, F., Roriz, A. K., Kovaleski, A., Segura, D. F., and Vera, M. T. 2014. "Differences in Sperm Storage and Remating Propensity between Adult Females of Two Morphotypes of the Anastrepha fraterculus (Diptera: Tephritidae) Cryptic Species Complex.” Bull. Entomol. Res. 104: 376-82.

[16] Yamada, S. M., and Selivon, D. 2001. "Rose, an Eye Color Mutation in a Species of the Anastrepha fraterculus Complex (Diptera: Tephritidae)." Ann. Entomol. Soc. Am. 94: 592-5.

[17] Alberti, A. C., Rodriguero, M. S., Cendra, P. G., Saidman, B. O., and Vilardi, J. C. 2002. "Evidence Indicating That Argentine Populations of Anastrepha fraterculus (Díptera: Tephritidae) Belong to a Single Biological Species." Ann. Entomol. Soc. Am. 95: 505-12.
[18] Arnqvist, G., and Nilsson, T. 2000. "The Evolution of Polyandry: Multiple Mating and Female Fitness in Insexts." Animal Beh. 60: 145-64.

[19] Mossinson, S., and Yuval, B. 2003. "Regulation of Sexual Receptivity of Female Mediterranean Fruit Flies: Old Hypotheses Revisited and New Synthesis Proposed." J. Insect Phys. 49: 561-7.

[20] Fritz, A. H., and Turner, F. R. 2002. "A Light and Electron Microscopical Study of the Spermathecae and Ventral Receptacle of Anastrepha suspensa (Diptera; Tephritidae) and Implications in the Female Influence of Sperm Storage." Arthop. Struc. Develop. 30: 293-313.

[21] Morgante, J. S., Malavasi, A., and Prokopy, R. J. 1983. "Mating Behavior of Wild Anastrepha fraterculus (Diptera: Tephritidae) on a Caged Host Tree." Florida Entomol. 66: 234-41.

[22] Segura, D., Petit-Marty, N., Sciurano, R., and Vera, M. T. 2007. "Lekking Behavior of Anastrepha fraterculus (Diptera: Tephritidae).” Florida Entomol. 90: 154-62. 